\title{
DIÁLOGOS ENTRE A CONCEPÇÃO DE LEITURA FREIRIANA E A ANÁLISE DO DISCURSO
}

\author{
Cristiane da Silva Ferreira ${ }^{1}$ \\ Anderson Ferreira ${ }^{2}$
}

\begin{abstract}
Resumo: O presente artigo tem por escopo promover um diálogo entre a ideia de leitura postulada por Paulo Freire em sua trajetória intelectual e a noçáo de leitura no quadro da Análise do Discurso contemporânea. Objetivamos, com isso, verificar a noçóes de leitura do mundo e leitura da palavra discutidas por Freire e operá-las em termos de condições sócio-históricas e culturais de produção do discurso e competência sociocultural concepçóes desenvolvidas no bojo dos estudos discursivos. Privilegiamos como aporte teórico-metodológico a Análise do Discurso em sua perspectiva enunciativodiscursiva. Para operar a produção da leitura discursiva, no quadro da supracitada associação, selecionamos um texto, tomado como discurso, para o qual o sujeito-leitor precisa mobilizar suas competências textual e genérica - leitura da palavra - bem como sua competência sociocultural - leitura do mundo - no bojo das condiçóes sócio-históricas e culturais que viabilizaram a manifestaçáo e circulação do referido texto. Os resultados apontam que a intersecção entre as ideias de Freire e a AD é bastante fecunda, sobretudo para se repensar o ensino de leitura, pois visa à uma prática de leitura crítica, que mobiliza as competências textual, genérica e sociocultural do sujeito-leitor.
\end{abstract}

Palavras-chave: Paulo Freire; Análise do Discurso; Ensino de leitura.

\section{DIÁLOGOS ENTRE LA CONCEPCIÓN DE LECTURA FREIRIANA Y EL ANÁLISIS DEL DISCURSO}

Resúmen: El presente artículo tiene por objeto promover un diálogo entre la idea de lectura postulada por Paulo Freire en su trayectoria intelectual y la noción de lectura en el marco del Análisis

1 Formada em Letras/ Português-Espanhol; Mestre e Doutora em Língua Portuguesa pela Pontifícia Universidade Católica de São Paulo, membro do grupo de Pesquisa "Memória e Cultura na Língua Portuguesa escrita no Brasil".

2 Doutorando pela PUC-SP, com estágio sanduíche pela Universidade do Minho, Portugal. (Braga, 2015) Possui Mestrado pela PUC-SP (São Paulo, 2014) e Especialização em Língua Portuguesa pela PUC-SP (São Paulo, 2010). Bacharelado e Licenciatura em Filosofia pela UNIFESP (Guarulhos, 2011/2013). Possui Graduação em Letras/Literatura pela UNG (Guarulhos, 2004). Desenvolve pesquisa na área de Língua Portuguesa, tendo como enfoques o estudo do texto e do discurso nas modalidades oral e escrita e do ensino de leitura numa perspectiva discursiva. É professor de Língua Portuguesa na rede municipal de São Paulo. No momento, é membro do grupo de pesquisa "Memória e Cultura da Língua Portuguesa escrita no Brasil" do Programa de Estudos Pós-graduados em Língua Portuguesa da PUC-SP. Bolsista CAPES. 
del Discurso contemporáneo. Objetivamos, con ello, verificar las nociones de lectura del mundo y lectura de la palabra discutidas por Freire y operarlas en términos de condiciones socio-históricas y culturales de producción del discurso y competencia sociocultural concepciones desarrolladas en el seno de los estudios discursivos. Privilegiamos como aporte teórico-metodológico el Análisis del Discurso en su perspectiva enunciativo-discursiva. Para operar la producción de la lectura discursiva, en el cuadro de la mencionada asociación, seleccionamos un texto, tomado como discurso, para el cual el sujeto-lector necesita movilizar sus competencias textual y genérica - lectura de la palabra - así como su competencia sociocultural - lectura del mundo - en el seno de las condiciones sociohistóricas y culturales que viabilizaron la manifestación y circulación de dicho texto. Los resultados apuntan que la intersección entre las ideas de Freire y la $\mathrm{AD}$ es bastante fecunda, sobre todo para repensar la enseńanza de lectura, pues apunta a una práctica de lectura crítica, que moviliza las competencias textual, genérica y sociocultural del sujeto lector.

Palabras-clave: Paulo Freire; Análisis del Discurso; Ensenãnza de lectura.

\title{
DIALOGUES BETWEEN THE CONCEPTION OF FREIRIAN READING AND DISCUSSION ANALYSIS
}

\begin{abstract}
This article aims to promote a dialogue between the idea of reading posited by Paulo Freire in his intellectual trajectory and the notion of reading in the framework of Contemporary Discourse Analysis. We aim, therefore, to verify the notions of reading the world and reading the word discussed by Freire and to operate them in terms of socio-historical and cultural conditions of discourse production and sociocultural competence conceptions developed in the bosom of discursive studies. We privilege as a theoretical-methodological contribution Discourse Analysis in its enunciative-discursive perspective. In order to operate the production of discursive reading, within the framework of the aforementioned association, we selected a text, taken as a discourse, for which the reader-reader needs to mobilize his textual and generic competences - reading the word as well as his sociocultural competence - reading the world - within the context of the socio-historical and cultural conditions which enabled the expression and circulation of said text. The results point out that the intersection between Freire's ideas and AD is very fruitful, especially in order to rethink reading teaching, since it aims at a critical reading practice that mobilizes the textual, generic and sociocultural competences of the subject-reader.
\end{abstract}

Keywords: Paulo Freire; Speech analysis; Teaching reading.

\section{CONSIDERAÇÓES INICIAIS}

O educador Paulo Freire, defensor de uma educação emancipadora e libertadora, concebe a leitura como uma prática ampla e complexa, que antecede à decodificação das palavras. A leitura está intimamente relacionada à capacidade de observação e entendimento do mundo que nos cerca. Em relação à linguagem escrita, não se trata de um gesto centrado na superficialidade do texto, mas no seu adentramento, posto que linguagem e realidade se prendem de modo dinâmico (FREIRE, 2011). Dessa maneira, uma leitura crítica resulta das relações entre textos em suas condições sócio-históricas e culturais de produção.

Nessa perspectiva, a Análise do Discurso (daqui em diante, AD) dialoga com a concepção de leitura freireana. Nascida em decorrência de investigações de práticas de leitura, a $\mathrm{AD}$, desde sua gênese, especula as relações entre elementos linguístico, sociais, históricos, culturais e ideológicos que permeiam o texto. Por isso, o texto 
não é visto apenas como uma materialidade tangível, isolada de suas condições sócio-históricas e culturais de produção, mas como unidade verbal pertencente a um gênero de discurso. Os textos, assim, em seu estatuto heterogêneo, podem ser produzidos por várias vozes e/ou associados a fotos, desenhos, imagens.

Essa heterogeneidade textual pertencente a determinado gênero de discurso, muitas vezes, não pode ser observada no texto que se apresenta a observação do sujeito-leitor. Desse modo, é preciso buscar elementos no exterior para poder propor uma leitura minimamente satisfatória, isto é, é necessário recorrer a elementos da história e da sociedade nas quais o sujeito está inserido. Em outras palavras, a produção da leitura na perspectiva discursiva exige a mobilização da história de leitura e da leitura do mundo do sujeito-leitor, bem como propunha Freire (2011). Com efeito, a leitura do mundo antecede a leitura da palavra, porém, na produção da leitura - no ato de ler - esses gestos são indissociáveis. Nesse sentido, a $\mathrm{AD}$ fornece um dispositivo de leitura que procura tomar num só golpe o linguístico e o extralinguístico. Em última instância, a $\mathrm{AD}$ procura tomar o texto como discurso, recuperando os lugares sociais onde a materialidade textual circula.

Nessa perspectiva, objetivamos, em primeiro lugar, retomar a discussão proposta por Paulo Freire acerca do ato de ler, e, em particular, mobilizar os conceitos de leitura do mundo e leitura da palavra, postulados por este educador. Em seguida, visamos a delimitar o lugar da AD no campo da Linguística e destacar seu estatudo interdisciplinar. Por último, operaremos uma análise do corpus selecionado, mobilizando as categorias de condições sócio-históricas e culturais de produção do discurso e de competência sociocultural.

\section{A CONCEPÇÃO DE LEITURA EM FREIRE}

Paulo Freire (1921-1997), educador e filósofo comprometido com a educação brasileira, problematizou a maneira pela qual a leitura é trabalhada na sala de aula. Em sua concepção, havia uma dualidade a ser superada: a da leitura que se esgota na decodificação das palavras e a da leitura que envolve uma concepção crítica do ato de ler. A crítica de Freire (2011) estendia-se à concepção de leitura centrada apenas na decodificação de palavras, frases e textos. De fato que, grande parte dos trabalhos com leitura, não considerava, de modo autêntico, a relação entre texto e suas condições sócio-históricas e culturais de produção. É certo que, no ensino da leitura, o processo de decodificação é relevante no início da alfabetização. Mas Freire se referia ao ensino de adultos não-alfabetizados, no entanto, com um amplo conhecimento do mundo onde viviam. 
No livro, A importância do ato de ler: em três artigos que se complementam, é possível verificar, na trajetória intelectual de Paulo Freire, suas reflexões no campo da alfabetização de adultos. ${ }^{3}$

Mais uma vez, ao longo dos anos, me ponho em frente de páginas em branco para escrever sobre o processo de alfabetização de adultos. Parece-me interessante salientar que o fato de haver tratado várias vezes este assunto não mata em mim nem sequer diminui um certo estado de espírito, típico de quem discute pela primeira vez um tema. É que para mim, não há assuntos encerrados. É por isso que penso e repenso o processo de alfabetização como quem está sempre diante de uma novidade, mesmo que, nem toda vez, tenha novidade sobre o que falar. Mas ao pensar e repensar a alfabetização, penso ou repenso a prática em que me envolvo. Não penso ou repenso o puro conceito, desligado do concreto, para, em seguida, descrevê-lo. (FREIRE, 2011, p. 49)

A suprarreferida citação consta no texto $O$ povo diz a sua palavra ou a alfabetização em São Tomé e Príncipe, artigo publicado originalmente em número especial da Harvard Educational Review, em fevereiro de 1981. Neste mesmo ano, Freire voltaria a refletir sobre o assunto com o mesmo entusiasmo "típico de quem discute pela primeira vez um tema". Uma nova colaboração foi apresentada, em novembro, no Congresso Brasileiro de Leitura, realizado em Campinas, São Paulo.

No artigo, $A$ importância do ato de ler, Freire (2011) realizará um percurso que abrirá veredas para uma nova concepção de leitura. Trata-se, como veremos mais adiante, de uma conjectura teórica e social da qual Paulo Freire não estava apartado. Tal conjectura fincará suas posições fora do campo do estruturalismo, onde o sujeito era, de modo contínuo, apagado. Assim, Freire inicia seu diálogo colocando o sujeito da leitura no centro das discussões. Ele rememora o seu passado, trazendo à tona momentos preenchidos de sentidos que marcaram sua infância em Recife.

O discurso memorialista de Freire (2011) objetiva separar, por meio de uma dialética irrepreensível, dois mundos. O primeiro é aquele onde a palavra escrita não pode ser percebida como uma inscrição. Trata-se do mundo daqueles onde a escrita marca certa cultura da qual ainda não se tem acesso, mas que é compreendida como superior. O segundo é o mundo da cultura escrita. No entanto, é no primeiro mundo que o sujeito-leitor é inserido de forma "absolutamente significativa" (FREIRE, 2011, p. 20). O discurso memorialista do educador instaura o sujeito inscrito na cultura escrita na leitura do mundo; o mundo que lhe cerca, um mundo onde vivências e aprendizagens se constituem mesmo antes da apropriação do código escrito.

3 O referido livro apresenta três textos de Paulo Freire: $O$ povo dir a sua palavra ou a alfabetização em São Tomé e Príncipe, publicado em 1981 e ampliado na presente edição; A importância do ato de ler, trabalho apresentado no Congresso Brasileiro de Leitura, em 1981 e Alfabetização de adultos e bibliotecas populares - uma introdução, palestra apresenta no XI Congresso Brasileiro de Biblioteconomia e Documentação em 1982. 
A leitura, então, não consiste em um gesto isolado da realidade social, já que implica uma relação indissociável entre o texto e suas condições sócio-históricas e culturais de produção. Logo, "linguagem e realidade se prendem dinamicamente" (FREIRE, 2011, p. 20). Nessa fase, a decodificação pura da palavra escrita não fornece os elementos necessários a uma compreensão crítica na produção da leitura. Neste ponto de tensão, Freire desenvolveu uma metodologia de alfabetização de jovens e adultos. $\mathrm{O}$ mergulho íntimo, no interior de si, permite ao educador desenvolver a empatia indispensável com aqueles que ainda não possuem o código escrito, mas são repletos de memória e de conhecimento do mundo que os cercam.

Freire (2011), ao revisitar-se, tinha como ponto de partida a realidade sociocultural, política e econômica do educando, suas vivências e seus saberes. Essa dialética mobilizava as palavras e os temas geradores utilizados pelo educador no processo de alfabetização. A pedagogia freireana propunha, assim, que as aulas de leitura produzissem a leitura da "palavramundo", ou seja, operassem como exercícios de cidadania, cuja criticidade pudesse despertar no sujeito-leitor modos de conscientização em vista a uma mobilidade sociopolítica. Desse modo, "não se pode entender o pensamento pedagógico de Paulo Freire descolado de um projeto social e político" (Gadotti, 2008, p.98).

Nessa direção, a educação em Freire é, antes de tudo, uma prática da liberdade, bem como enfatizou Francisco Correia Weffort (1937) em Reflexões sociológicas sobre uma pedagogia da liberdade, presente em (FREIRE, 1967, p. 4).

A visão da liberdade tem nesta pedagogia uma posição de relevo. É a matriz que atribui sentido a uma prática educativa que só pode alcançar efetividade e eficácia na medida da participação livre e crítica dos educandos. É um dos princípios essenciais para a estruturação do círculo de cultura, unidade de ensino que substitui a "escola", autoritária por estrutura e tradição.

Essa visão libertária se estende à concepção de leitura no bojo das reflexões freireanas. A conjuntura teórica e social dos escritos da Educaşão como prática da liberdade culmina com os questionamentos da leitura estruturalista, sobretudo, na França. Neste período, a $\mathrm{AD}$ começa a elaborar um projeto de leitura, particularmente, com Michel Pêcheux (1938-1983) que tematizava de modo claro as deficiências das outras teorias, então, em pleno vigor. Nesse aspecto, um estudioso da envergadura de Freire, embora longe, geograficamente, das questões políticas emergentes em Paris da década de 1960, estava a par das transformações que vinham ocorrendo no mundo.

Assim como a noção de leitura em AD, Freire visa a ressignificar a ideia de uma leitura única, cujo sentido já estaria posto. Ao contrário. A concepção de leitura postulada por Freire (2011) exige um adentramento do texto, que responda à inquieta procura do sujeito-leitor, como notamos nesta passagem:

[...] A leitura verdadeira me compromete de imediato com o texto que a mim se dá e a que me dou e de cuja compreensão fundamental me vou tornando também sujeito. Ao ler não me acho no puro encalço da inteligência do texto como se fosse ela produção apenas de seu autor ou de sua autora. Esta forma 
viciada de ler não tem nada que ver, por isso mesmo, com o pensar certo e com o ensinar certo (FREIRE, 2016, p. 29).

Nessa senda, Freire (2016) destaca a importância do sujeito-leitor no processo de leitura, pois o seu mundo e sua história de leitura são partes intrínsecas do texto. O pensar certo a que o autor se refere compreende que não há respostas definitivas e imunes a discussões, uma vez que não podemos estar demasiados certos de nossas certezas. "A insistência na quantidade de leituras sem o devido adentramento nos textos a serem compreendidos [...] revela uma visão mágica da palavra escrita. Visão que urge ser superada" (FREIRE, 2011, p. 27).

A interação, na produção da leitura, do sujeito-leitor com a materialidade textual e discursiva torna-se essencial para a construção de uma educação emancipadora. A autonomia e o diálogo se completam na produção da leitura. O sujeito-leitor, dessa maneira, pode emancipar-se no momento em que é capaz de produzir seu próprio ato de fala, interagindo com o outro em vista à alteridade. Nesse quadro, o sujeito-professor pode propor a produção da leitura como negociação dos efeitos de sentido, mobilizando a história de leitura e a leitura do mundo dos sujeitos-alunos.

O educador assume, assim, o papel de mediador. No quadro da pedagogia freiriana, o sujeito-professor convoca para encenação didática o professorproblematizador. Este gesto visa a ressignificar a imagem do sujeito-professor como detentor do saber, cabendo-lhe a função de conduzir o educando à conquista de sua autonomia, pois só assim o sujeito-aluno poderá intervir no mundo que o cerca (GADOTTI, 2008).

Em sua trajetória intelectual e política, Paulo Freire fornece uma enorme contribuição ao campo da educação. Contudo, o Projeto do educador brasileiro não delimitou fronteiras, não estabeleceu territórios fixos, e, por isso, suas reflexões extrapolam, até os dias de hoje, o campo da educação. Freire deixou muitas veredas abertas às novas pesquisas e também promoveu um diálogo contínuo com outros campos de conhecimento. É, portanto, invocando este dialogo que propomos uma interface com a concepção de leitura em Freire (2011) com os propósitos da AD, que se marca, na contemporaneidade, como um dispositivo de leitura.

\section{A ANÁLISE DO DISCURSO: UM DISPOSITIVO DE LEITURA}

A AD é uma disciplina que tem sua gênese marcada por uma interdisciplinaridade. Ela nasce de considerações postuladas no campo Linguística, da História e da Psicanálise. A AD se constitui no cerne de uma inquietação que lhe é peculiar. Essa condição a inscreve como disciplina fronteiriça entre os campos de conhecimento. Dessa maneira - adepta a mudanças e transformações, a AD mobiliza novos gestos de leitura, construindo um corpus de análise mais aberto e heterogêneo.

Gestada no início dos anos 1960, na França, em um período dominado pelo estruturalismo, a AD pôde reivindicar o direito de pronunciar-se sobre a questão da 
leitura. Como sinaliza Possenti (2009), a AD nasceu como resposta à problemática do ato de ler. Naquela conjuntura teórica e política, os intelectuais franceses se deparavam como inúmeras questões, cujos debates e contestações eram de diversas ordens. Destacamos, para os propósitos do presente artigo, a atuação do filósofo Michel Pêcheux com sua versão peculiar da AD, cuja proposta consistia em romper com a concepção tradicional de linguagem, fazendo intervir o discurso.

Conforme Orlandi (2005, p. 16), passou-se a considerar a "língua inserida no mundo e sua relação com os sujeitos que a enunciam e as situações em que se produz o dizer". Nesse cenário teórico, a AD mobiliza a Linguística, o materialismo histórico fornecido por Louis Althusser (1918-1990) de suas leituras de Karl Marx (1818-1883) e, mais tarde, a Psicanálise lacaniana que fornece elementos à concepção de sujeito e subjetividade. Assim, Linguística, Marxismo e Psicanálise se articularam, num primeiro momento, para compor o constructo teóricometodológico da AD. Essa associação, a princípio, tem por escopo compreender como um objeto simbólico - o discurso - produz efeitos de sentido. Este novo gesto de leitura se opunha à análise do conteúdo, na época, bastante em voga.

Vale reforçar que, embora pertença à área da Linguística, a AD é um campo heterogêneo e interdisciplinar. A depender das disciplinas e corpus evocados na análise, a $\mathrm{AD}$ apresenta-se como uma disciplina de fronteira instável. Como enfatiza Maingueneau (2007), o estudo do discurso não pode ser esgotado por uma disciplina, mas deve ser tomado como objeto de estudo por várias disciplinas que possuem interesses distintos e pontos de vista diversos.

Mas os pontos a se destacar vão além do estatudo heterogêneo da AD. Da mesma forma que os estudos de Paulo Freire solicitam um diálogo contínuo com vários campos de conhecimento, a $\mathrm{AD}$ sobrevive ao apagamento da conjuntura que a tornou possível pelo fato de compreender que o enraizamento de sua gênese era uma leitura possível (MAINGUENEAU, 1990) e não conclusiva. Desse modo, no quadro teórico-metodológico da $\mathrm{AD}$, as condições sócio-históricas e culturais de produção do discurso são medulares na produção da leitura. Tais condições é o que Freire chamou de leitura do mundo.

No esforço de retomar a infância distante, a que já me referi, buscando a compreensão do meu ato de ler o mundo particular em que me movia, permitam-me repetir, re-crio, re-vivo (sic), no texto que escrevo, a experiência vivida no momento em que ainda não lia a palavra. E algo que me é importante, no contexto geral de que venho falando, emerge afora insinuando a sua presença no corpo destas reflexões. (FREIRE, 2011, p. 22).

Esta e outras passagens descrevem sem cessar uma história/memória, uma dada sociedade e uma cultura. Mas, no quadro teórico-metodológico da AD, as condições sócio-históricas e culturais não pertencem ao sujeito, mas ao discurso. Dessa forma, não se trata de investigar o que um sujeito ético-moral tem a nos dizer, mas, efetivamente, o que o discurso diz e não diz. O procedimento que Freire constitui - a rememorar na sua infância, pessoas, os objetos, os lugares, enfim, as práticas culturais - pode ser evocado pelo sujeito-leitor na produção da leitura. 
Este procedimento liga-se, de modo intrínseco, às condições sócio-históricas e culturais de produção do discurso e podemos nomeá-lo como uma competência sociocultural.

Desse modo, não há um sentido verdadeiro e único a ser investigado pela $\mathrm{AD}$, pois ela derroga a noção de imanência do significado. Ou seja, não credita à palavra um significado primeiro, original e fixo

\begin{abstract}
[...] o sentido de uma palavra, de uma expressão, de uma proposição, etc., não existe em si mesmo (isto é, em sua relação de transparência com a literalidade do significante, mas, ao contrário, é determinado pelas posições ideológicas que estão em jogo no processo sócio-histórico no qual as palavras, expressões e proposições são produzidas ( isto é, reproduzidas). (PÊCHEUX, 1995, p.160).
\end{abstract}

Em outras palavras, a noção de sentido é produzida face aos lugares que o sujeito ocupa no discurso, o qual deve ser reportado às suas condições sóciohistóricas e culturais de produção do discurso. O sentido, portanto, não é dado $a$ priori, mas construído no decorrer da produção da leitura.

É possível, então, associar a história da leitura e a leitura do mundo do sujeito-leitor a uma competência sociocultural historicamente determinada. Sua determinação ocorre pelos processos de constituência que, de fato, são sociais, históricos e culturais. Nessa ótica, a leitura do mundo consubstancia a leitura da palavra. Em outros termos, podemos propor que a competência sociocultural congrega-se as competências linguística, textual e genérica. $\mathrm{O}$ sujeito-leitor, de acordo com o texto com o qual interage, pode mobilizar mais uma que outra. As competências, assim, "interagem para produzir uma interpretação. Com estratégias diferentes, pode-se chegar à mesma interpretação" (MAINGUENEAU, 2013, p. 48).

Enfatizamos que com gestos de leitura distintos o sujeito-leitor pode chegar aos mesmos ou, também, diversos efeitos de sentido. É, por isso, que insistimos, nessa aproximação entre a concepção de leitura freireana e a $\mathrm{AD}$, na percepção crítica incitada pela produção da leitura discursiva. Contudo, a nossa proposta no presente artigo tem por objetivo, por um lado, tomar a leitura do mundo como categoria discursiva, fundada nas condições sócio-históricas e culturais de produção do discurso e na competência sociocultural do sujeito-leitor, e, por outro, tomar a leitura da palavra como competências linguística, textual e genérica. Em outras palavras, postular, nessa associação entre educação e discurso, "um compreensão crítica do ato de ler [...] que se antecipa e se alonga na inteligência do mundo" (FREIRE, 2011, p. 19).

Passamos, então, à produção da leitura discursiva do corpus selecionado.

\title{
A PRODUÇÁO DA LEITURA DISCURSIVA: O ATO DE LER
}

Texto [1] 


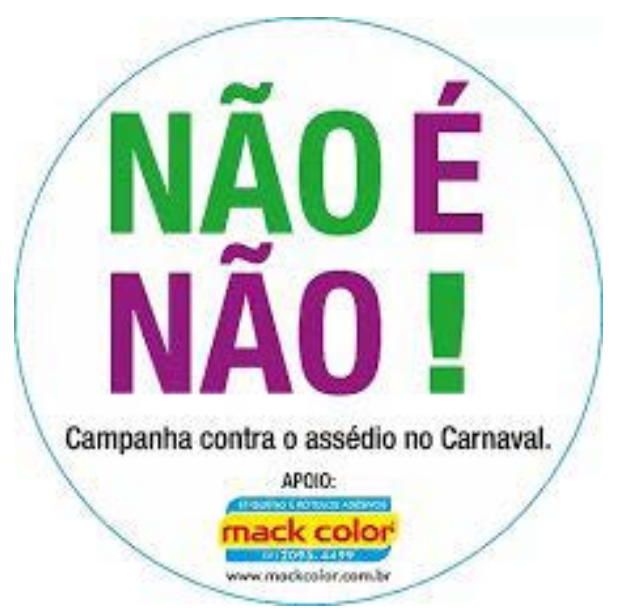

A gráfica de autoadesivos da cidade São Paulo, Mack Color Etiquetas Adesivas, distribui, em 2017, um milhão de adesivos com o enunciado: "Não é Não!" [texto [1], acima], a fim de reforçar a campanha \#AconteceuNoCarnaval, lançada naquele ano. A estratégia da empresa, entre outras coisas, visava a coletar relatos de foliões que presenciaram ou vivenciaram algum tipo de violência durante o carnaval. A partir desta iniciativa, a Secretaria de Estado de Direitos Humanos e Políticas para Mulheres e Idosos (SEDHMI) do estado do Rio de Janeiro teve a ideia de lançar, no ano de 2018, uma campanha contra o assédio sexual durante o carnaval: "Carnaval é curtição, respeita o meu não". A iniciativa consiste em conscientizar homens e mulheres para luta contra todo tipo assédio. Mas, antes de adentrarmos a leitura do texto [1], é preciso discutir as noções de competências linguística e textual; sobre as quais apenas suscitamos anteriormente.

O ensino da leitura, de modo geral, foca nas competências linguística e textual quando se objetiva alcançar certa "compreensão do texto", ou mesmo uma "interpretação". Aliás, no momento em que se focaliza o cotexto, isto é, as marcas gramaticais que determinado texto carrega, solicita-se do sujeito-leitor a evocação de um leitor-modelo, capaz de reconhecer ou assimilar essas marcas referenciais no interior da materialidade textual. Elas remetem a noção de leitura da palavra, postulada por Freire (2011) e é objeto da Linguística Textual.

Não obstante, quando se objetiva, para além do cotexto, investigar os modos de difusão e manifestação do texto, bem como suas relações com os espaços sociais e os sujeitos em dada sociedade reivindica-se do sujeito-leitor a evocação de um leitor-modelo, capaz operar "um movimento do mundo à palavra e da palavra ao mundo" (FREIRE, 2011, p. 29). Esse movimento tem como objeto o discurso e pode se apreendido, materialmente, pelos gêneros de discurso. Por isso, a relevância da mobilização de uma competência genérica.

Graças ao nosso conhecimento dos gêneros do discurso, não precisamos prestar uma atenção constante a todos os detalhes de todos os enunciados que ocorrem à nossa volta. Em um instante somos capazes de identificar um dado enunciado como sendo um folheto publicitário ou como uma fatura e, 
então, podemos nos concentrar apenas em um número reduzido de elementos (MAINGUENEAU, 2013, p. 70).

Nesse sentido, podemos relacionar as competências linguística e textual à escolarização e as competências genérica e sociocultural a uma forma de impregnação (MAINGUENEAU, 2013). ${ }^{4}$

Por isso, é que ao chegar à escolinha particular de Eunice Vasconcelos [...] já estava alfabetizado. Eunice continuou e aprofundou o trabalho de meus pais. Como ela, a leitura da palavra, da frase, da sentença, jamais significou uma ruptura com a "leitura" do mundo. Com ela, a leitura da palavra, foi a leitura da "palavramundo" (FREIRE, 2011, p. 24, ênfases do autor).

No texto [1], na produção da leitura, o sujeito-leitor tende a deslocar para o segundo plano as competências linguística e textual e busca mobilizar as competências sociocultural e genérica. Maingueneau (2013) enfatiza que, numa comunicação efetiva, os interlocutores se comportam como convêm os gêneros de discurso dos quais participam. Esse "comportamento" é, segundo o autor, antes de tudo uma competência genérica. É preciso, todavia, considerar os possíveis lugares de circulação dos gêneros de discurso, bem como os sujeitos discursivos que dele participam.

Como sinaliza o enunciado no texto [1], trata-se de uma "campanha contra o assédio no Carnaval". O gênero de discurso suscita, desse modo, algumas coordenadas:

[1] Uma finalidade reconhecida.

[2] O estatudo de parceiros legítimos.

[3] O lugar e momento legítimos.

[4] Um suporte material.

[5] Uma organização textual.

[6] Recursos linguísticos específicos.

Em [5] e [6], o gênero de discurso exige a mobilização das competências linguística e textual. No entanto, o sujeito-leitor, no texto [1], supondo a coerência do texto, utiliza em "menor grau" estas competências, uma vez que o texto não oferece muitas dificuldades no que tange ao seu corpo verbal. Os termos $<$ Não $>$, $<$ é $><$ campanha $>$, <assédio $>$, <contra $><$ carnaval $>$, por exemplo, pertencem a um vocabulário acessível ao sujeito-leitor inserido nos lugares onde o adesivo

4 A escola tem se dedicado ao ensino de gêneros textuais - textos realizados em gêneros de discurso. Contudo, a realidade tangível com a qual o sujeito se defronta é o gênero de discurso. Essa separação metodológica faz-se necessária para ressaltar que a maioria dos indivíduos é desprezada por não saber se comunicar com facilidade em certos gêneros de discurso valorizados socialmente: um currículo, uma moção num evento sindical, uma monografia, uma palestra, uma entrevista de emprego etc. Logo, o ensino do gênero de discurso, no campo do ensino, precisa ser discutido. 
circula, provavelmente, onde circulam foliões nos grandes centros urbanos em época de carnaval.

Em [4], o suporte material é reivindicado pela própria materialidade do gênero, qual seja: uma etiqueta adesiva. $\mathrm{O}$ suporte será aquele onde a etiqueta será colada: muros, estabelecimentos comerciais, instituições públicas, carros, instrumentos musicais, camisetas etc.

Em [1], [2] e [3], o gênero de discurso evoca as coordenadas para aquilo que Freire (2011) chama de leitura do mundo. Em última instância, o gênero de discurso mobiliza uma competência sociocultural. Assim, a leitura do mundo pode ser invocada por intermédio do seguinte raciocínio: esse adesivo "colado na parede", neste lugar e momento, visa a interrogar a quem e por quê?

A partir dessa interrogação o sujeito-leitor passa a participar do gênero, assumindo um papel social. Não se trata, porém, de uma conscientização gratuita e automática, como sugere a campanha da Secretaria de Estado de Direitos Humanos e Políticas para Mulheres e Idosos (SEDHMI), mas o sujeito-leitor deve assumir um papel social em conjunto com uma mudança de mentalidade. As coordenadas [1], [2] e [3] do gênero de discurso, então, serão focalizadas, no presente artigo, com intuito de constituir as condições sócio-históricas e culturais de produção do discurso que recobrem o estatuto dessa mentalidade. Para tanto, é necessário mobilizar uma competência sociocultural de sujeito-leitor "modelo".

O raciocínio supracitado não tem nada de banal. Aliás, o sujeito-leitor pode iniciar a produção da leitura pela finalidade do gênero. Com efeito, todo gênero, como afirma Maingueneau (2013), implica uma modificação da situação da qual participa. Assim, a finalidade de um adesivo/folheto fixado em lugares públicos e/ou privados visa a chamar à atenção a determinada questão. No caso do texto [1], trata-se de uma questão social, na verdade, de um problema social nas interrelações entre homens e mulheres. De outra forma, o lugar e momento que o gênero implica "carnaval de 2017" evoca, também, o estatuto de parceiros legítimos. Logo, o gênero de discurso determina de quem parte a fala e a quem ela é dirigida.

Neste ponto, há uma imbricação complexa entre a voz da empresa "Mack Color Etiquetas Adesivas" e a voz que diz "Não é Não". Nesse sentido, o sujeitoleitor pode recorrer à sua leitura do mundo - a uma competência sociocultural para lembrar que em nossa sociedade existem campanhas contra ou a favor de algo, que essas campanhas, geralmente, são destinadas a um público mais vasto e, ainda, que elas pretendem mudar ou condicionar certos comportamentos sociais.

No texto [1] a campanha visa a conscientizar os indivíduos em uma dada sociedade e em dado momento histórico a denunciar todo tipo de assédio que aconteça durante o carnaval. A voz que "fala", portanto, não pode ser remetida, de modo direto, à empresa em questão, mas a uma comunidade discursiva mais ampla de sujeitos que assumem, numa dada sociedade, um discurso de combate ao assédio. Essa voz se dirige, assim, não apenas aos foliões do carnaval, mas, de modo amplo, a homens e mulheres inseridos nessa sociedade. 
Ora, justo é que se façam campanhas em sociedade democráticas. Contudo, é preciso interrogar por que o lugar e o momento legítimos seria o período de carnaval. Em busca de uma transformação social entendida como "processo histórico em que subjetividade e objetividade se prendem dialeticamente" (FREIRE, 2011, p. 42), o sujeito-leitor pode participar do gênero de modo a descobrir no discurso aquilo que está encoberto, isto é, o não-dito.

Nos últimos anos, temos acompanhado diversos casos de assédio contra as mulheres. Vejamos algumas webmanchetes:

\section{Homem é detido por ejacular em mulher dentro de ônibus no Centro de SP}

Ele assinou termo circunstanciado por importunaçăo ofensiva ao pudor e foi liberado.

Fonte 1. G1. Disponível em: https://g1.globo.com/sp/sao-paulo/noticia/homem-e-detido-porejacular-em-mulher-dentro-de-onibus-no-centro-de-sp.ghtml Acesso em: 12 dez. 2017

\section{Homem do DF que ejaculou em passageira durante voo foi liberado pela polícia}

Ele foi autuado por 'importunação ofensiva ao pudor' e aguarda em liberdade convocação da Justiça.

Tipificação do crime não prevê prisão e 'depende de avaliação do delegado', disse Polícia Civil.

Fonte 2. G1. Disponível em: https://g1.globo.com/df/distrito-federal/noticia/homem-do-df-queejaculou-em-passageira-durante-voo-foi-liberado-pela-policia.ghtml> Acesso em: 15 dez 2017.

\section{Atrizes denunciam produtor de Hollywood por assédio sexual}

Harvey Weinstein, um dos maiores produtores de Hollywood, foi protagonista de um drama da vida real esta semana. Ele é apontado como autor de diversos abusos ocorridos nos bastidores das grandes produçōes do cinema norte-americano

Fonte 3. Correio Braziliense. Disponível em http://www.correiobraziliense.com.br/app/noticia/ diversao-e-arte/2017/10/11/interna_diversao_arte,633117/a-historia-de-assedio-de-weinsteinhollywood.shtml > Acesso em 19 out. 2017. todo.

Podemos ficar por aqui. São apenas três casos de centenas que há no mundo

A leitura do mundo que nos cerca (FREIRE, 2011) pode fornecer as bases para compreendermos que a campanha de conscientização contra o assédio no carnaval - apesar de produzir um efeito de sentido de inclusão de homens e mulheres - institui-se como um contra-discurso, num sociedade, marcadamente, machista, misógina e sexista. No entanto, na contemporaneidade, o debate, neste 
campo, vem extrapolando os lares de mulheres sócio, política e economicamente desassistidas e vulneráveis a situação de risco. Das delegacias de polícia passou-se às mídias televisas, radiofônicas, impressas e digitais. Das periferias das cidades e zonas rurais, viu-se o problema avultar-se, atravessando toda sociedade.

O conceito de assédio sexual, então, tornou-se um objeto de luta. Cem mulheres francesas publicaram em carta, em janeiro de 2018, no jornal Le Monde um manifesto pela liberdade dos homens "flertar". Aliás, a liberdade do flerte nunca lhes fora retirada, tampouco concedida. Em contrapartida, o Movimento \#MeToo (eu também) encabeçado por feministas norte-americanas questiona a prática do flerte. O discurso das norte-americanas valida o discurso contido no texto [1], no sentido de denunciar a violência sexual e a desigualdade entre homens e mulheres.

A discussão entre parte das mulheres francesas e parte das mulheres norte-americanas sinaliza que o gênero de discurso da campanha do texto [1] apenas pode ser viabilizado devido às condições sócio-históricas e culturais da contemporaneidade. Onde o discurso machista, misógino e sexista existe, mas já se confronta com um contra-discurso, feminista, democrático e em favor da igualdade de gêneros.

Na produção da leitura do texto [1], o sujeito-leitor é incitado a refletir o motivo pelo qual, em uma sociedade denominada civilizada, é preciso "conscientizar" homens e mulheres a lutar contra o assédio. Como sugere Freire (2011), o entendimento do texto implica, numa leitura crítica, o discernimento das relações entre texto e suas condições sócio-históricas e culturais de produção. A condição de produção do texto [1] atravessa sua condição de existência material. Em outras palavras, o carnaval, nessa ótica, é o símbolo da "liberdade" sexual, é o lugar onde podemos extravasar nossa alegria, deixar nossas tristezas, esquecer ressentimentos e contas a pagar. É o lugar, por excelência, dionisíaco. Também, é o lugar onde podemos transgredir tempo, subverter o espaço, burlar normas sociais, travestir nossos corpos, rostos e identidade, por fim, usar a máscara antissocial.

Por isso, o gênero de discurso "campanha" solicita enunciadores que assumem o papel social da vigilância, da normalidade, da civilidade e do respeito "Não é Não!". A leitura do mundo implica a leitura da palavra. Logo, não é possível que a produção da leitura se esgote na decodificação pura da palavra escrita, conforme argumenta Freire (2011). Mas também a leitura da palavra implica, de modo incontestável, a leitura do mundo. $\mathrm{Na} \mathrm{AD}$, essa associação pode ser apreendida pela constituição das condições sócio-históricas e culturais da materialidade discursiva. Essa noção surge como medular na produção da leitura discursiva e, com ela, podemos aventar as competências necessárias para os efeitos de sentido na produção da leitura.

\section{CONSIDERAÇÓES FINAIS}

A concepção de leitura em Freire, pautada na leitura do mundo e na leitura da palavra, põe em destaque o sujeito-leitor, cujo conhecimento de mundo dialoga com o texto, ocasionando assim o seu adentramento. Por isso, conforme Freire, realidade e linguagem são indissociáveis. Essas ideias convergem com a noção 
de leitura postulada pela $\mathrm{AD}$, um dispositivo de leitura que concebe as condições sócio-históricas e culturais de produção do discurso.

Os resultados da análise do corpus selecionado apontam que a produção da leitura, na perspectiva enunciativo-discursiva, visa a um gesto de leitura crítico e autônomo, que evoca do sujeito-leitor as competências linguística, textual, genérica e, sobretudo, sociocultural. Este gesto é responsável pela produção efeitos de sentido do discurso, cujo átomo é a negociação entre os enunciadores. Portanto, esse movimento revela que o diálogo estabelecido neste estudo entre a concepção de leitura em Freire e a noção de leitura postulada pela AD se mostrou relevante, acenando, inclusive, para uma ressignificação acerca do ensino da leitura em parte das escolas brasileiras. Ensino que ainda centra-se, de modo prioritário, na materialidade linguística. Ficamos, assim, abertos ao diálogo.

\section{REFERÊNCIAS}

BRANDÃO, Helena Nagamine. Introdução à Análise do Discurso. 2.ed. Campinas, SP: UNICAMP, 2004.

FERNANDES, Cleudemar Alves. Análise do Discurso: reflexões introdutórias. 2.ed. São Carlos: Claraluz, 2007.

FREIRE, Paulo. A importância do ato de ler em três artigos que se complementam. 51.ed. São Paulo: Cortez, 2011.

Pedagogia da autonomia: saberes necessárias à prática educativa. 43. ed., São Paulo: Paz e Terra, 2011.

A educação como prática da liberdade. Rio de Janeiro. Paz e Terra, 1967.

GADOTTI, Moacir. Reinventando Paulo Freire na escola do século 21. In: TORRES, Carlos Alberto (Org.) Reinventando Paulo Freire no século 21. São Paulo: Editora e Livraria Instituto Paulo Freire, 2008. Série Unifreire, p. 91-107.

MAINGUENEAU, Dominique. Análise de Discurso: a questão dos fundamentos.

Caderno de Estudos Linguísticos. Campinas (19) p. 65-74, 1990.

. A Análise do Discurso e suas fronteiras. Matraga, Rio de Janeiro, v.14, n.20, 2007, pp. 13-37.

Análise de textos de comunicação. Tradução Cecília P. de Souza \& Délcio Rocha. $6^{\circ}$ ed. ampl. São Paulo: Cortez, 2013.

POSSENTI, Sírio. Questões para analista do discurso. São Paulo: Parábola, 2009. 